\title{
La gran reforma Social de 1900. Filantropía social y emergencia de las primeras leyes obreras
}

\author{
María Victoria Jiménez Martínez \\ Universidad de Alcalá, España \\ victoria.jimenezm@uah.es
}

La obra titulada La gran reforma social de 1900 realiza un estudio sistemático sobre la aprobación de las primeras leyes laborales en 1900, destacando su especial incidencia económica y social. Este proceso se basaba en la necesidad de superar los efectos perniciosos del liberalismo clásico, mediante la intervención normativa en la cuestión social. Es justamente durante la Restauración cuando surge la problemática de la emergencia de una respuesta jurídica a las incipientes relaciones industriales claramente descompensadas, donde existía un claro antagonismo injusto entre el capital y el factor trabajo. Ello suponía la necesidad de aprobar importantes disposiciones normativas de protección jurídica de los trabajadores, concediéndoles importantes derechos laborales, así como la necesidad de reconocer institucionalmente un mínimo de protección social por la vía de las contingencias profesionales. Esta protección se orientó especialmente a los colectivos más necesitados de tutela: en concreto, a la protección social del accidente de trabajo, la limitación del trabajo de niños y mujeres, la regulación del descanso dominical para el conjunto de la clase obrera y el control jurisdiccional de los primeros derechos laborales reconocidos legalmente.

En este libro encontramos un análisis de una reforma social de gran calado: un cambio social estructural, que fue una respuesta valiente e innovadora de la 
clase política de la Restauración. Desde la política se intentó atender el problema de la cuestión social, anticipándose al futuro y como contramedida ante el peligro de la revolución obrera. La opción se canalizó mediante una legislación urgente, teniendo en cuenta que debía contar con un sustrato ideológico e ilustrado, que facilitara el consenso relativa a las medidas a adoptar. Esta opción permitía llevar a cabo una política legislativa, que observaba los postulados krausistas del "intervencionismo científico". Esta posición suponía una opción ante la inactividad institucional y el aplazamiento de las soluciones por parte de los poderes públicos a los problemas de la clase obrera.

En esta monografía se revisan los ejes esenciales de la política legislativa reformista. En concreto, se presta atención a su íntima conexión con la propia transformación del sistema liberal, mediante el estudio de la necesidad del intervencionismo social, que superaba así el liberalismo clásico. Asimismo, se atiende la situación económica y social del momento. Especialmente, se presta atención a la labor consultiva previa realizada por la Comisión de Reformas Sociales, posteriormente desarrollada por el Instituto de Reformas Sociales, creado en 1903: precisamente, un año antes del propio reconocimiento de la ley de descanso dominical. A su vez, el libro considera el contexto de conflictividad laboral y social, así como el alto grado de incumplimiento de la reforma laboral y social por parte de patronos y obreros. Este problema de fondo sería el fundamento de la existencia de un control judicial, que implicaba la necesidad de ordenar la garantía jurisdiccional de los nuevos derechos obreros.

Este libro tiene como objeto el análisis de las tres grandes materias que conformaron la primera acción legislativa de la denominada cuestión social. Se analizan conjunta y coordinadamente la primera intervención legislativa en el trabajo subordinado; se estudia el trabajo de mujeres y niños, los accidentes de trabajo y el descanso semanal, que eran los temas más sensibles, y que se encuentran estrechamente relacionados entre sí. Los tres pilares de la acción reformista de 1900 fueron la Ley de accidentes de trabajo de 30 de enero 1900 (Gaceta del 31), la Ley del trabajo de mujeres y niños de 13 de marzo de 1900 (Gaceta del 14) y la Ley de descanso dominical de 3 de marzo de 1904 (Gaceta del 4). Tales leyes conforman la base de la legislación obrera de España. 
Las leyes de principios de siglo xx nos permiten reflexionar sobre el proceso de consolidación del inicio de la legislación social española. En este trabajo se presentan los retos y los límites que tenía dicho proceso reformador. Ya la doctrina del momento destacó que "al fin, aunque tarde, se ha comenzado a enmendar en España la política de abandono que, casi tradicionalmente, venía en uso entre nuestros hombres de Estado con respecto al problema llamado social" (Buylla, y Alegre, 1900, p. 340). Efectivamente, la nota común del proceso reformador está en la necesidad de forjar una respuesta institucional a los problemas sociales: la búsqueda de la aprobación de unas primeras leyes sociales que compensen la situación de pobreza de la clase proletaria. En este contexto se abre camino la legislación protectora del obrero, debiendo introducir los límites del propio sistema capitalista y superar la cultura y los principios individualistas consagrados en el propio ordenamiento jurídico liberal. Se buscó una solución comprendiendo que era inasumible la posición abstencionista de los poderes públicos. El gobierno no podía permanecer impasible e indiferente ante los problemas sociales estructurales y ante el acentuado movimiento de opinión a favor de las reformas sociales, reclamadas por parte de la clase trabajadora. Esta obra analiza una labor legislativa ingente y ambiciosa para la época, dirigida por gobiernos de corte conservador y fundamentada en una importante labor de estudio de las condiciones de trabajo y vida de los obreros. Todo ello supuso el estudio del modelo de producción industrial, mediante los trabajos de la Comisión de Reformas Sociales, lo cual dio lugar a un intervencionismo científico e ilustrado, hasta entonces inédito en España.

La presente monografía aborda un tema muy novedoso, pues se examinan los fundamentos, fines y medidas principales de las primeras leyes obreras: una visión de conjunto y coordinada, que de forma transversal estudia el tratamiento de la cuestión social por el Estado liberal regeneracionista de comienzos del siglo xx. Ciertamente, estos temas se han analizado, pero de forma autónoma. En cambio, este libro intenta conectar las distintas disposiciones objeto de análisis y sacar conclusiones desde una visión transversal. Si bien es cierto que el período de la Restauración ha sido abordado desde el punto de vista histórico, político, jurídico, social y económico, es preciso destacar que, sobre todo, se trata de estudios de carácter general. En este sentido, hacía falta un análisis monográfico 
de la gran reforma social de principios del siglo pasado, que ha fundamentado el actual sistema de derechos sociales en España. El lector tiene, pues, la oportunidad de adentrarse en una etapa apasionante de la historia española. Se trata de un estudio cuidado, bien documentado, que se nutre de abundantes notas a pie de página y donde el lector podrá encontrar una magnífica colección de referencias bibliográficas sobre el tema. En definitiva, estamos en presencia de un libro que completa los distintos estudios históricos previos relativos a la evolución del derecho del trabajo en España.

\section{Bibliografía}

Libro: La gran reforma social de 1900. Filantropía social y emergencia de las primeras leyes obreras.

Autor: José Eduardo López Ahumada

Editorial: Editorial Cinca

Lugar: Madrid

Año: 2018

Cómo citar el artículo: Jiménez, M.V. (2020). La Gran Reforma Social de 1900. Filantropía y emergencia de las primeras leyes obreras. Derecho Global, Estudios sobre Derecho y Justicia, V. (14) pp. 201-204 